\title{
Tropheryma whipplei in Feces of Patients with Diarrhea in 3 Locations on Different Continents
}

\author{
Gerhard E. Feurle, Verena Moos, Olfert Landt, Craig Corcoran, Udo Reischl, Matthias Maiwald
}

We examined fecal specimens of patients with diarrhea from 3 continents for Tropheryma whipplei and enteropathogens. T. whipplei was most common in South Africa, followed by Singapore and Germany. Its presence was associated with the presence of other pathogens. An independent causative role in diarrhea appears unlikely.

7 ropheryma whipplei is the causative agent of Whip1 ple disease (1). The organism has also been detected in the feces of healthy or asymptomatic persons $(2,3)$ and in the feces of patients with diarrhea (4-6). A causative role in gastroenteritis has been proposed.

To investigate the role of enteric T. whipplei, we examined fecal specimens of patients with diarrhea using conventional methods and PCR to detect enteric pathogens and T. whipplei. Our aim was to collect epidemiologic evidence regarding a causative role of T. whipplei in diarrhea.

\section{The Study}

The 3 participating sites were the Molecular Biology Laboratory, AMPATH (Centurion, South Africa); the Department of Pathology and Laboratory Medicine at KK Women's and Children's Hospital (Singapore); and the Institute of Microbiology and Hygiene at the University Hospital Regensburg (Regensburg, Germany). We examined fecal samples from patients

Author affiliations: DRK Krankenhaus, Neuwied, Germany

(G.E. Feurle); Charité-Universitätsmedizin Berlin, Berlin, Germany (V. Moos); TIB MOLBIOL Syntheselabor GmbH, Berlin, Germany (O. Landt); National Reference Laboratory AMPATH, Centurion, South Africa (C. Corcoran); Institute of Clinical Microbiology and Hygiene, University Hospital Regensburg, Regensburg, Germany (U. Reischl); KK Women's and Children's Hospital, Singapore (M. Maiwald); National University of Singapore, Singapore (M. Maiwald); Duke-National University of Singapore Graduate Medical School, Singapore (M. Maiwald)

DOI: https://doi.org/10.3201/eid2703.200182 with diarrhea that were submitted for microbiological laboratory diagnosis; we used a combination of conventional tests and multiplex PCRs covering the pathogens shown in Table 1, with differences owing to local arrangements (Appendix, https://wwwnc. cdc.gov/EID/article/27/3/20-0182-App1.pdf).

We investigated a total of 590 fecal samples. In South Africa, 97 of 100 targeted samples were usable. In Singapore, 193 of 200 targeted specimens contained sufficient material; of these, 19 were originally submitted for bacterial culture, 77 for rotavirus antigen testing, and 97 for both. In Germany, we tested samples from 300 patients. In South Africa and Singapore, patients were mainly children, both outpatients and inpatients. In Singapore, the total included 13 immunocompromised children with hematologic/oncologic diseases and 1 with a short bowel syndrome. In Germany, all were inpatients and mostly elderly, about one quarter from the hematologic/oncologic ward (Figure).

Overall, 56 patients had positive test results for $T$. whipplei in the feces: 17 (17.5\%) in South Africa, 29 (15\%) in Singapore, and 10 (3.3\%) in Germany. The frequency distribution of the organisms detected is shown in Table 1. In South Africa, T. whipplei was the most common fecal organism, followed by Shigella, rotavirus, and adenovirus. In Singapore, rotavirus was the most frequently detected organism, followed by norovirus, T. whipplei, and Salmonella. In Germany, Clostridioides difficile was the most frequently detected organism, followed by T. whipplei and Blastocystis hominis; viruses were not sought in Germany. The frequency of $C$. difficile likely reflects the high proportion of elderly inpatients.

Fecal specimens testing positive for T. whipplei averaged 0.91 other pathogens per specimen, in contrast to only 0.46 per specimen in those testing negative for T. whipplei ( $p=0.0001$; Table 2). Similarly, of the fecal specimens testing positive for T. whipplei, $69.6 \%$ contained other pathogens, in contrast to only $34.5 \%$ of the specimens testing negative for T. whipplei $(\mathrm{p}<0.0001$; Appendix Table 1). Thus, specimens con- 
taining T. whipplei contained other pathogens about twice as frequently as specimens without $T$. whipplei. In Singapore, 1 specimen contained 4 pathogens: $T$. whipplei, Blastocystis, astrovirus, and Dientamoeba.

Data on watery consistency and the presence of blood in feces were available for South Africa and Singapore, and microscopy data (e.g., erythrocytes, mucus, yeast cells) were available for South Africa (Appendix Table 2). There was no apparent relationship between these parameters and the presence of $T$. whipplei. Thus, an independent diarrheagenic role of T. whipplei was not apparent from these macroscopic and microscopic findings.

An association between the presence of Campylobacter and T. whipplei (Appendix Table 3) became apparent. Of 534 T. whipplei-negative fecal samples, $21(3.9 \%)$ were positive for Campylobacter across all sites, whereas $8(14.3 \%)$ of 56 T. whipplei-positive samples were positive for Campylobacter. This difference was statistically significant $(p=0.0035)$. In relative terms, specimens carrying T. whipplei contained Campylobacter 3 times more commonly than those without T. whipplei. When looking at the frequency ranking for all pathogens, Campylobacter rose from seventh position in $T$. whipplei-negative samples to being the fourth most common enteropathogen in $T$. whipplei-positive samples in South Africa and from fourth to second position in Singapore, whereas the position in Germany remained unchanged (Appendix Table 4).

The mechanisms underlying the CampylobacterTropheryma association remain unclear, but may include similar modes of acquisition. T. whipplei can be transmitted by the fecal-oral route $(7,8)$. Campylobacter spp. are commensals in the gut of a variety of animals, especially poultry; the main infection routes for Campylobacter species are foodborne and fecaloral transmission (9). Both T. whipplei and Campylobacter can be found in sewage (9-11).

Our study's first limitation was that it was done in real-life settings of diagnostic laboratories where the routine investigations were supplemented by additional PCR tests (Appendix). Pathogens tested and diagnostic techniques differed among the 3 laboratories but were identical within each laboratory between the specimens with and without T. whipplei. However, this diversity may even increase the robustness of data. The proportions of fecal samples with no pathogen detected were $81 \%$ in Germany, $57 \%$ in South Africa, and $29 \%$ in Singapore. These findings reflect not only the absence of pathogens but also the pathogen spectrum investigated; a higher number of different pathogens investigated will lead to more positive results, and
Singapore had the most comprehensive tests. A high rate of negative findings limits the analyses concerning co-infections of T. whipplei with other pathogens.

Second, our study did not include asymptomatic controls, as did the Global Enteric Multicenter Study $(12,13)$. In South Africa, T. whipplei was the most frequent fecal microorganism, followed by Shigella, rotavirus, and adenovirus, in descending order, the last

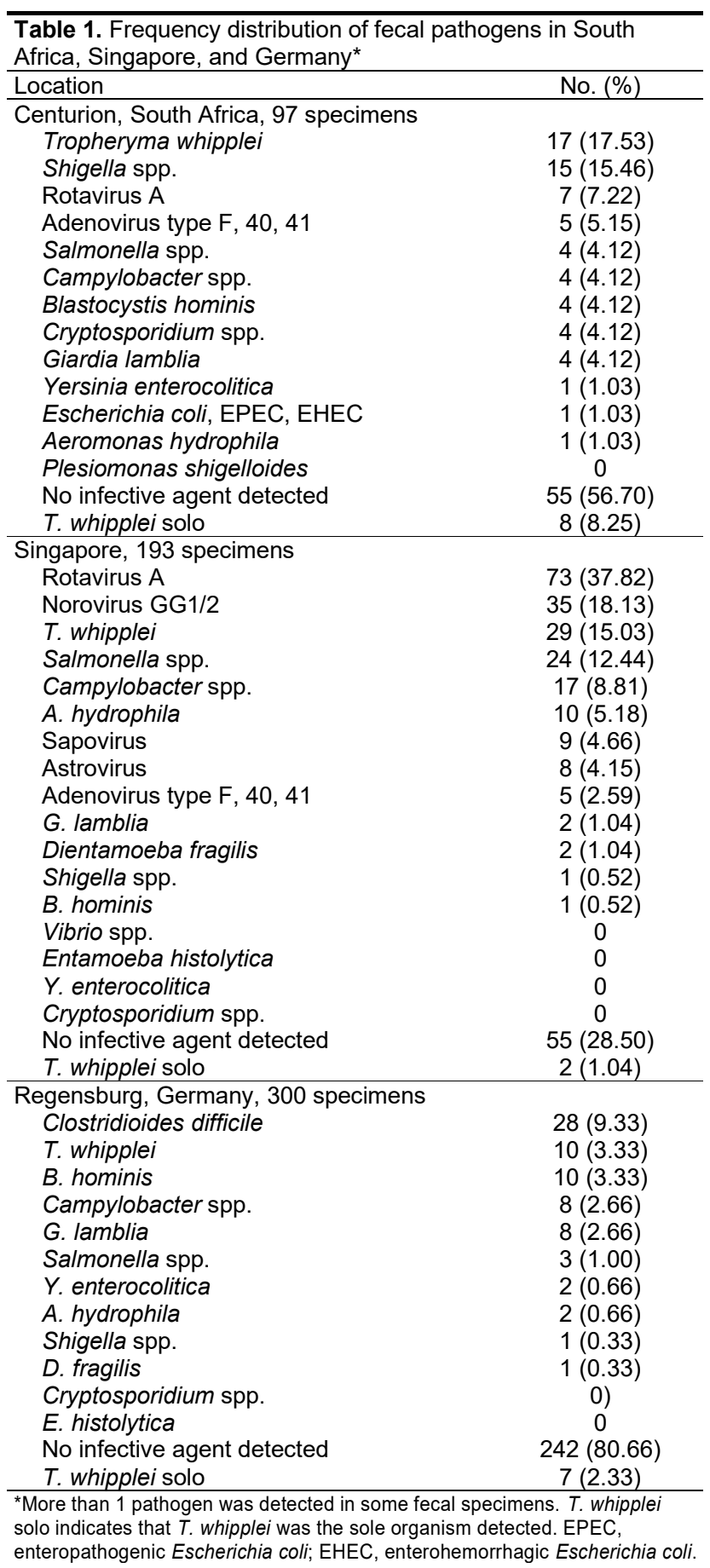


Table 2. Numbers of enteropathogens in fecal specimens with and without Tropheryma whipplei in South Africa, Singapore, and Germany*

\begin{tabular}{|c|c|c|c|c|}
\hline \multirow[b]{2}{*}{ Location } & \multicolumn{2}{|c|}{ Specimens without T. whipplei } & \multicolumn{2}{|c|}{ Specimens with T. whipplei } \\
\hline & No. specimens & $\begin{array}{c}\text { No. (rate) of } \\
\text { enteropathogens }\end{array}$ & No. specimens & $\begin{array}{c}\text { No. (rate) of } \\
\text { enteropathogens }\end{array}$ \\
\hline Centurion, South Africa & 80 & $40(0.50)$ & 17 & $10(0.59)$ \\
\hline Singapore & 164 & $145(0.88)$ & 29 & $38(1.31)$ \\
\hline Regensburg, Germany & 290 & $60(0.21)$ & 10 & $3(0.30)$ \\
\hline Total† & 534 & $245(0.46)$ & 56 & $51(0.91)$ \\
\hline
\end{tabular}

${ }^{*}$ Total numbers and rates per specimen of all enteropathogens across all specimens collected at each site; multiple pathogens in a single specimen were counted as multiple entries.

tIncidence rate $\chi^{2}, p<0.0001$.

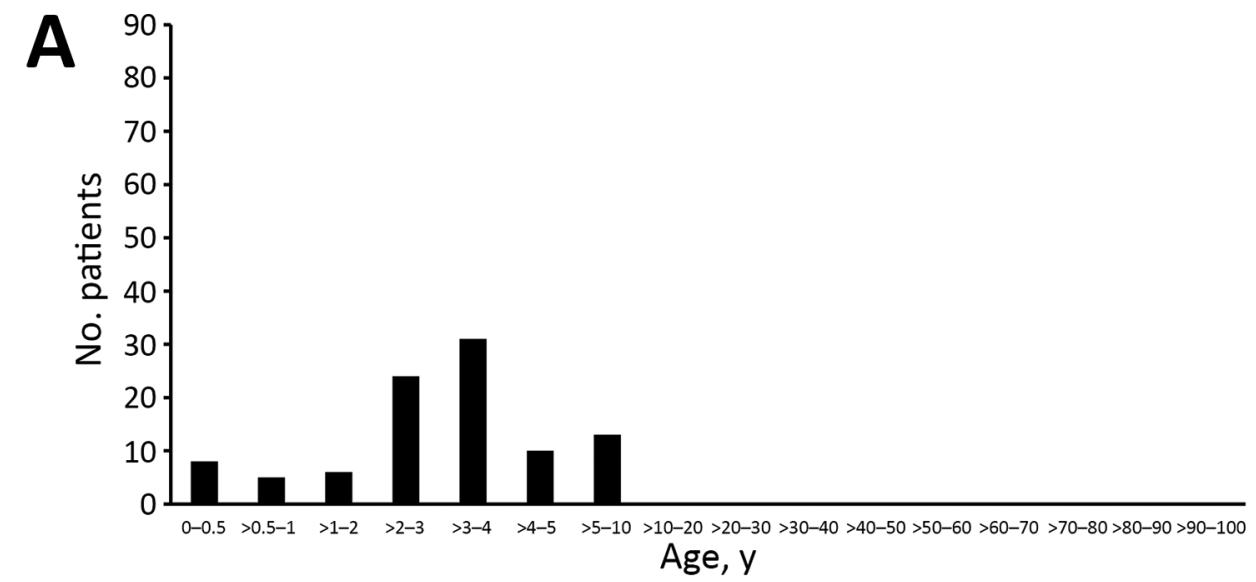

Figure. Age distribution of patients at 3 sites in study of Tropheryma whipplei in feces of patients with diarrhea: A) Centurion, South Africa; B) Singapore; and C) Regensburg, Germany.

B
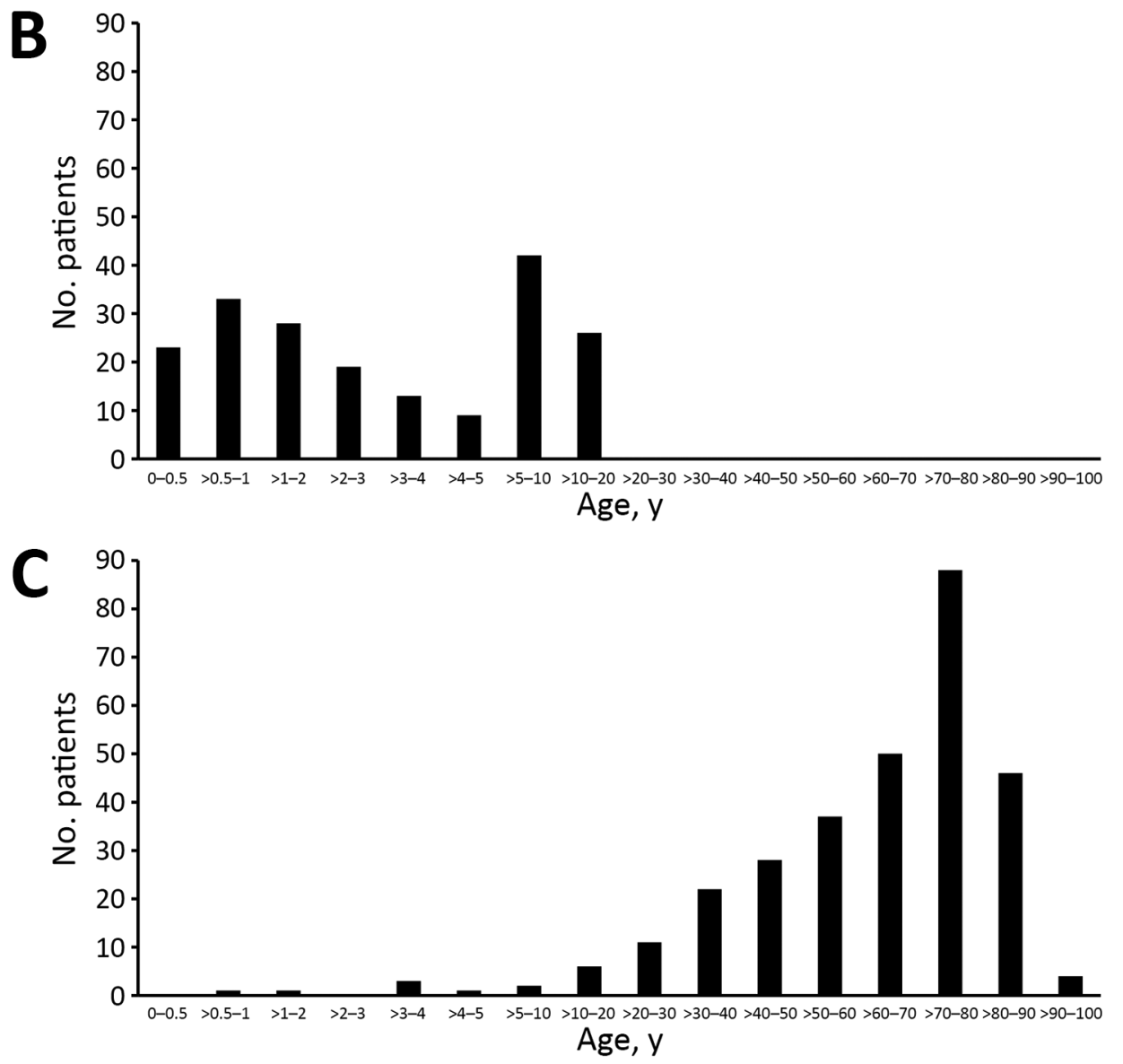
3 exactly as in the Global Enteric Multicenter Study. In Singapore, T. whipplei was third after rotavirus and norovirus, but the ranking of rotavirus may be an artifact because rotavirus antigen was the most frequent ordered laboratory test.

We postulate that the different prevalence of pathogens at the 3 locations (Table 1) is related not just to the different diagnostic strategies but probably also to different climate, development, and hygiene. The Sustainable Development Goals indices for water, sanitation, and hygiene were 68, 66, and 90 in South Africa; 98, 99, and 97 in Singapore; and 100, 100, and 100 in Germany (14). These data reflect the order of prevalence of T. whipplei in feces in the 3 locations, which is in accordance with a prevalence approaching 50\% in children in Laos (15).

\section{Conclusions}

Using diagnostic specimens from microbiology laboratories on 3 continents, we were able to confirm that T. whipplei can be found frequently in the feces of patients with diarrhea $(4,5)$. Across the 3 locations, the numbers of traditional enteropathogens were significantly increased in specimens also containing T. whipplei, and we found an association between the presence of T. whipplei and Campylobacter. Our findings support the hypothesis that enteric T. whipplei may not be causative for diarrhea but may possibly be a result of different sanitary and climatic conditions.

\section{Acknowledgments}

We thank Annette Moter and Thomas Schneider for their contributions to the process of conceiving the study protocol. We also thank the staff of the Microbiology Laboratory at KK Women's and Children's Hospital, Singapore, in particular, Liat Hui Loo and Han Yang Soong, for their contributions to conducting the Singapore part of the study. We thank John C. Allen for help with statistical analyses.

\section{About the Author}

Dr. Feurle is an emeritus professor of internal medicine and gastroenterology at the DRK Krankenhaus Neuwied, a teaching hospital of the University of Bonn, Germany. His primary research interest is Whipple disease.

\section{References}

1. Schneider T, Moos V, Loddenkemper C, Marth T, Fenollar F, Raoult D. Whipple's disease: new aspects of pathogenesis and treatment. Lancet Infect Dis. 2008;8:179-90. https://doi.org/10.1016/S1473-3099(08)70042-2

2. Fenollar F, Trani M, Davoust B, Salle B, Birg ML, Rolain JM, et al. Prevalence of asymptomatic Tropheryma whipplei carriage among humans and nonhuman primates. J Infect Dis. 2008;197:880-7. https:/ / doi.org/10.1086/528693
3. García-Álvarez L, Pérez-Matute P, Blanco JR, Ibarra V, Oteo JA. High prevalence of asymptomatic carriers of Tropheryma whipplei in different populations from the north of Spain. Enferm Infecc Microbiol Clin. 2016;34:340-5. https://doi.org/10.1016/j.eimc.2015.09.006

4. Raoult D, Fenollar F, Rolain JM, Minodier P, Bosdure E, $\mathrm{Li}$ W, et al. Tropheryma whipplei in children with gastroenteritis. Emerg Infect Dis. 2010;16:776-82. https:/ / doi.org/10.3201/eid1605.091801

5. Fenollar F, Minodier P, Boutin A, Laporte R, Brémond V, Noël G, et al. Tropheryma whipplei associated with diarrhoea in young children. Clin Microbiol Infect. 2016;22:869-74. https://doi.org/10.1016/j.cmi.2016.07.005

6. Vinnemeier CD, Klupp EM, Krumkamp R, Rolling T, Fischer N, Owusu-Dabo E, et al. Tropheryma whipplei in children with diarrhoea in rural Ghana. Clin Microbiol Infect. 2016;22:65.e1-3. https:// doi.org/10.1016/j.cmi.2015.09.022

7. Keita AK, Brouqui P, Badiaga S, Benkouiten S, Ratmanov P, Raoult D, et al. Tropheryma whipplei prevalence strongly suggests human transmission in homeless shelters. Int J Infect Dis. 2013;17:e67-8. https://doi.org/10.1016/j.ijid.2012.05.1033

8. Ramharter M, Harrison N, Bühler T, Herold B, Lagler H, Lötsch F, et al. Prevalence and risk factor assessment of Tropheryma whipplei in a rural community in Gabon: a community-based cross-sectional study. Clin Microbiol Infect. 2014;20:1189-94. https://doi.org/10.1111/1469-0691.12724

9. Pitkanen T, Hanninen ML. Members of the family Campylobacteraceae: Campylobacter jejuni, Campylobacter coli. In: Rose JB, Jiménez-Cisneros B, editors. Global Water Pathogen Project. East Lansing (MI): Michigan State University and UNESCO; 2017. https://doi.org/10.14321/waterpathogens.23

10. Maiwald M, Schuhmacher F, Ditton HJ, von Herbay A. Environmental occurrence of the Whipple's disease bacterium (Tropheryma whippelii). Appl Environ Microbiol. 1998;64:760-2. https:// doi.org/10.1128/AEM.64.2.760-762.1998

11. Schöniger-Hekele M, Petermann D, Weber B, Müller C. Tropheryma whipplei in the environment: survey of sewage plant influxes and sewage plant workers. Appl Environ Microbiol. 2007;73:2033-5. https://doi.org/10.1128/AEM.02335-06

12. Kotloff KL, Nataro JP, Blackwelder WC, Nasrin D, Farag TH, Panchalingam S, et al. Burden and aetiology of diarrhoeal disease in infants and young children in developing countries (the Global Enteric Multicenter Study, GEMS): a prospective, case-control study. Lancet. 2013;382:209-22. https://doi.org/10.1016/S0140-6736(13)60844-2

13. Liu J, Platts-Mills JA, Juma J, Kabir F, Nkeze J, Okoi C, et al. Use of quantitative molecular diagnostic methods to identify causes of diarrhoea in children: a reanalysis of the GEMS case-control study. Lancet. 2016;388:1291-301. https://doi.org/10.1016/S0140-6736(16)31529-X

14. Lozano R, Fullman N, Abate D, Abay SM, Abbafati C, Abbasi N, et al.; GBD 2017 SDG Collaborators. Measuring progress from 1990 to 2017 and projecting attainment to 2030 of the health-related Sustainable Development Goals for 195 countries and territories: a systematic analysis for the Global Burden of Disease Study 2017. Lancet. 2018;392:2091-138. https:/ / doi.org/10.1016/S0140-6736(18)32281-5

15. Keita AK, Dubot-Pérès A, Phommasone K, Sibounheuang B, Vongsouvath M, Mayxay M, et al. High prevalence of Tropheryma whipplei in Lao kindergarten children. PLoS Negl Trop Dis. 2015;9:e0003538. https://doi.org/10.1371/journal. pntd.0003538

Address for correspondence: Gerhard E. Feurle, DRK

Krankenhaus Neuwied, Innere Medizin I, Marktstrasse 104, 56564

Neuwied, Germany; email: g.e.feurle@t-online.de 